\title{
FAMÍLIAS NA REDE DE SAÚDE MENTAL: UM BREVE ESTUDO ESQUIZOANALÍTICO'
}

\author{
Roberta Carvalho Romagnoli
}

\begin{abstract}
RESUMO. Essa pesquisa estudou a dinâmica de funcionamento das famílias de portadores de transtorno mental do CERSAM Teresópolis de Betim, cidade da Região Metropolitana de Belo Horizonte. A amostra se constituiu de 08 famílias atendidas no Programa de extensão Saúde Mental e Família, em uma parceira da prefeitura local com a PUC-Minas. Os dados foram coletados através do cadastro familiar, que abordava as seguintes categorias: situação familiar, renda familiar, emergência da psicopatologia e funcionamento familiar. Os resultados atestam que a baixa renda familiar, a cronicidade da doença mental e sua respectiva dependência, a necessidade de cuidado ininterrupto, a crise que advém da eclosão da doença, tudo isso integra um território existencial marcado pela dor e pelo sofrimento, formando um modo de existência grupal que tem na doença mental seu eixo de sustentação.
\end{abstract}

Palavras-chave: saúde mental, família, esquizoanálise.

\section{FAMILIES AT THE MENTAL HEALTH NETWORK: A BRIEF SCHIZOANALYTICAL ESSAY}

\begin{abstract}
This research studied the dynamics of families dealing with mental issues at 'CERSAM - Teresopolis de Betim', a city located in the surroundings of Belo Horizonte (MG). The samples comprised eight families being assisted by a social program involving Mental Health and Family - Programa de extensão Saúde Mental e Família - in partnership with the town hall of Betim and PUC- Minas (Catholic University of Minas Gerais). Data were collected from a family dossier, which showed the following categories: family situation, income, emergency of psychopathology and the family dynamics. The results showed that, a low family income, the chronic nature of the mental disease leading to dependence, the crisis after the disease appeared, and the need for continuous care, are factors that contribute to a existential territory marked by pain and suffering, thus, developing a form of 'existence in group' that finds support in the mental condition.
\end{abstract}

Key words: Mental health, family, schizoanalysis.

\section{FAMILIAS EN LA RED DE SALUD MENTAL: UN BREVE ESTUDIO ESQUIZOANALÍTICO}

\begin{abstract}
RESUMEN. Esta investigación estudió la dinámica de funcionamiento de las familias de personas que sufren de trastorno mental de CERSAM - Teresópolis de Betim, ciudad de la Región Metropolitana de Belo Horizonte (MG). La muestra se constituyó de 08 familias atendidas en el Programa de extensión Salud Mental y Familia, en una sociedad del Ayuntamiento de Betim con la universidad PUC-Minas. Los datos fueron recogidos a través de un censo familiar, que contemplaba las siguientes categorías: situación, renta y funcionamiento familiar y emergencia de la psicopatología. Los resultados atestan que la baja renta familiar, la cronicidad de la enfermedad mental y su respectiva dependencia, la necesidad de cuidado ininterrumpido, la crisis que conlleva la eclosión de la dolencia, todo eso integra un territorio existencial marcado por el dolor y por el sufrimiento, formando un modo de existencia grupal que posee en la enfermedad mental su eje de sustentación.
\end{abstract}

Palabras-clave: salud mental, familia, esquizoanálisis.

1 Apoio: Fundo de Incentivo à Pesquisa - FIP da Pontifícia Universidade Católica de Minas Gerais.

* Psicóloga, Doutora em Psicologia Clínica. Professora do Departamento de Psicologia da Pontifícia Universidade Católica de Minas Gerais. 
Esse texto pretende apresentar a pesquisa realizada em Betim, no ano de 2004, com as famílias usuárias do Centro de Referência em Saúde Mental - CERSAM Teresópolis, da rede de saúde mental desse município. Localizada na Região Metropolitana de Belo Horizonte, a 30 quilômetros da capital, a cidade de Betim possui uma população de 335.236 habitantes e sua média de crescimento é de $5 \%$ ao ano. Caracterizase por ser um pólo industrial que atua como atrativo para imigrantes do interior e de outros estados, que chegam em busca de trabalho e ascensão social. Em pesquisa recente, o Departamento de Ciência Política da UFMG constatou que o município, apesar de ser a oitava arrecadação de ICMS do país, possui uma renda per capita de $\mathrm{R} \$ 203,22$ e é considerada a cidade mais violenta da região. Betim possui oito regionais, dentre as quais a regional Teresópolis, onde se localiza o CERSAM, que presta serviço às famílias entrevistadas por essa pesquisa. Essa região, conforme a Universidade Federal de Minas Gerais (2004), tem estimativa de 120.000 habitantes, e sua ocupação se deu em 1979, de forma desordenada e irregular, sendo a maioria composta por invasões. Nessa regional, $46 \%$ dos chefes de domicílio ganham até um salário-mínimo por mês e vivem abaixo da linha da pobreza.

Os CERSAM's são dispositivos estratégicos de atendimento à urgência psiquiátrica em regime aberto, e fazem parte da rede de atenção que dá suporte aos serviços substitutivos, oferecendo atividades que escapam à lógica segregacionista dos hospitais psiquiátricos. A clientela do CERSAM Teresópolis é prioritariamente composta por casos graves de psicose e neurose adultas, que necessitam de acompanhamento e encaminhamento. Nesses casos o envolvimento familiar é permanente e inevitável, pois a reinserção do portador de transtorno mental na sociedade ocorre prioritariamente nos espaços familiares, em famílias em geral carentes e sem preparo para prover cuidado familiar e subjetivo.

Nesse contexto está inserido o Programa de Extensão em Saúde Mental e Família, com atendimento a famílias, o qual faz parte do Programa de Extensão em Saúde Mental, implantado desde fevereiro de 2001 e desenvolvido em uma parceria da PUC-Minas com a Prefeitura Municipal de Betim. Tal programa tem como objetivo introduzir o aluno de Psicologia no cotidiano do trabalho profissional em saúde mental, a partir dos pressupostos da Reforma Psiquiátrica Brasileira. Os alunos atuam em diversos dispositivos da rede de saúde mental, deparando-se com a realidade desse campo de trabalho, desmistificando preconceitos e aprimorando a reflexão crítica acerca da loucura.

O trabalho com as famílias dos usuários dessa rede teve início em agosto de 2003, a partir de uma demanda da Coordenação do Programa de Saúde Mental da referida prefeitura. Essa atividade extensionista conta com quatro estagiários, que realizam o atendimento das famílias em duplas. Eles fazem uma entrevista inicial com as famílias encaminhadas pelos profissionais do serviço, preenchendo, em conjunto com os responsáveis, o cadastro familiar elaborado pelo programa. Esse cadastro busca conhecer a realidade das famílias e sua dinâmica de funcionamento, a fim de orientar a condução da primeira entrevista dos alunos com a família e colher dados para a pesquisa, simultânea ao programa. $\mathrm{O}$ atendimento das famílias se dá em seis encontros, podendo estes ser renovados ou não, de acordo com a avaliação da equipe. Os estagiários têm ainda supervisão semanal dos casos atendidos e preenchem um relatório de acompanhamento.

Sem dúvida, a psicose e a neurose graves possuem sintomatologias complexas, que geram estresse e grandes desestabilizações no grupo familiar. Focando a questão da desestabilização do grupo e, sobretudo, a possibilidade de invenção que este possui, utilizaremos as idéias de Deleuze e Guattari (1995), em sua proposta esquizoanalítica, para examinar a dinâmica de funcionamento dessas famílias ${ }^{2}$. Em contraposição a uma forma de pensar dicotômica, essa vertente convoca a imanência, a exterioridade das forças que atuam na realidade, buscando conexões, abrindo-se para o que afeta. Nesse sentido, a subjetividade deve ser pensada como um sistema complexo e heterogêneo, constituído não só pelo sujeito, mas também pelas relações que este estabelece. Essas relações denunciam a exterioridade de forças que incidem sobre cada um de nós e sobre as famílias, e atuam rizomaticamente, de uma maneira transversal, ligando processualmente a subjetividade a situações, ao coletivo, ao heterogêneo:

Trata-se menos de uma identidade de ser, (...)
do que de uma persistência processual. A
ênfase não é mais colocada no Ser, como
equivalente ontológico geral, o qual (...)
envolve, delimita e dessingulariza o
processo, mas sobre a maneira de ser, a

Essas idéias recebem vários nomes, inclusive por parte dos próprios autores, dentre eles: esquizoanálise, novo paradigma ético-estético, pragmática, filosofia do virtual. Entretanto, mais do que o nome, a proposta da obra é tanto realizar uma crítica ao modus vivendi atual quanto operar para produzir novas maneiras de viver e de pensar. 
maquinação para criar o existente, as práxis geradoras de heterogeneidade e complexidade (Guattari, 1992, p. 139).

A subjetividade é constituída por múltiplas linhas e campos de forças que atuam ao mesmo tempo: linhas duras, que detêm a divisão binária de sexo, profissão, camada social, e que sempre classificam, sobrecodificam os sujeitos; e linhas flexíveis, que possibilitam o afetamento da subjetividade e criam zonas de indeterminação, permitindo-lhe agenciar. Esse afetamento da subjetividade pelo que não é ela, pelas relações efetuadas, pela intersecção com o "fora", forma um agenciamento. Quando isso ocorre, linhas de fuga são construídas, convergindo em processos que trazem o novo (Deleuze \& Parnet, 1998). Esses processos são sempre coletivos, conectando-se ao que está aquém e além do sujeito e construindo novos territórios existenciais.

Na leitura esquizoanalítica, essa é a dinâmica dos processos de subjetivação. A realização de deslocamentos da subjetividade se dá a partir dos afetamentos do "fora", portadores de forças estranhas que pedem uma decifração. Essas forças, quando entram em contato com a subjetividade, aumentam a impressão de estranheza do mundo e conduzem a rupturas de sentido. De acordo com Rolnik (1999), as rupturas de sentido ocorrem quando a subjetividade é lançada na processualidade da vida e se vê forçada a trilhar novos caminhos via agenciamentos maquínicos, produtivos. Neste contexto, a decifração do que a vida nos apresenta é o movimento próprio da criação.

As linhas citadas acima compõem o território existencial, o modo de existência de cada um de nós, e também possibilitam que se exerça a invenção, a criação processual da vida. Esse raciocínio implica ainda a apreensão da realidade através de superfícies, de planos simultâneos que coexistem sem hierarquia e nem determinação. São eles: o plano de organização, o plano de consistência e o plano de imanência.

De acordo com Deleuze e Guattari (1995), ao plano de organização correspondem as imagens sociais, as figuras existentes, as idéias feitas, os corpos prontos. Esse plano organiza a realidade de maneira dicotômica e dissociativa, codificando-a, registrando-a em processos classificatórios, via operações de transcendência. Nessa superfície cada termo ganha sentido opondo-se a outro. O plano de consistência é o plano invisível de expansão da vida, composto pelas forças moleculares que atravessam o campo social. É nesse plano que se dão os encontros e os agenciamentos que vão gerar novos sentidos, novas formas de expressão. Nessa superfície, por sua vez, não há oposição, mas uma variação contínua. Por outro lado, o que sustenta estes dois planos é o plano de imanência, que possibilita e sustenta as relações entre as forças componentes da realidade, consistindo no "meio" em que tudo se dá - dimensão de fluxos e conexões. Os fluxos, em estado de imanência, estão presentes em todos os planos, e o que se altera é sua composição: esta é segmentar no plano de organização e fluida no plano de consistência. Segundo Deleuze \& Guattari (1996), a forma segmentar estanca a circulação da vida e opera cortes e recortes que produzem o modo de a espécie humana se colocar no mundo, e tem como objetivo estabelecer métodos de hierarquização e de organização. Por outro lado, a forma fluida é mutante e criadora e corresponde à possibilidade de agenciar, de construir uma linha de fuga, um outro território existencial.

O plano de organização sustenta as linhas duras da subjetividade, enquanto o plano de consistência sustenta suas linhas flexíveis, que podem se transformar em linhas de fuga que se dirigem para a invenção, para a estranheza da vida. Um território existencial é formado quando os elementos heterogêneos que compõem a subjetividade ganham alguma homogeneidade, determinada composição. Esse território localiza-se na interface entre o que se repete e é conhecido e o que pode afetar, desterritorializar, produzir um outra composição, via agenciamentos. Nesse sentido, cada família habita um meio, circula em formas de se relacionar, constituindo um território que envolve marcas, sons, silêncios, atitudes, comportamentos, mitos, crenças, segredos próprios de cada família. Essas marcas ganham, por insistência, alguma homogeneização, conquistada pela repetição e comunhão desses elementos heterogêneos entre as subjetividades que integram o grupo.

O movimento da vida, sua processualidade, está em inventar territórios, em deixar-se afetar pelo que vem de "fora", desterritorializar e reterritorializar novamente. Vale lembrar que o território existencial é composto tanto pelo que está estabelecido quando pelo que pode vir a ser. "Um território está sempre em vias de desterritorialização, ao menos potencial, em vias de passar a outros agenciamentos, mesmo que o outro agenciamento opere por reterritorialização" (Deleuze \& Guattari, 1997, p. 137). São as circunstâncias, os elementos que se estabelecem entre os encontros que podem ou não trazer outras marcas, romper com sentidos conhecidos e fundar novos territórios existenciais.

Nessa perspectiva nos propomos a estudar as famílias dos portadores de transtorno mental, pesquisando qualitativamente seus territórios existenciais, em sua ligação ou não com a 
processualidade da vida. Em um momento em que a saúde pública possui programas desenvolvidos especificamente para atender a demanda da família, tornam-se necessários estudos que produzam conhecimento sobre o tema, que contribuam, inclusive, para a construção de novos dispositivos clínicos e apostem na capacidade de invenção e na potência desses grupos. Diante da escassez de alternativas que esse tipo de família apresenta a si mesmo e a nós, diante das rupturas de sentido que enfrenta, achamos pertinente estudar sua capacidade de subjetivação.

\section{METODOLOGIA E MÉTODO}

Visando a estudar os territórios existenciais das famílias de portadores de transtornos mentais, realizamos uma pesquisa de campo qualitativa, que buscou a compreensão das percepções e significados que esses grupos constroem em seu cotidiano familiar. Sobre a pesquisa qualitativa, podemos afirmar que:

A epistemologia qualitativa é um esforço na busca de formas diferentes de produção de conhecimento em psicologia que permitam a criação teórica acerca da realidade plurideterminada, diferenciada, irregular, interativa e histórica, que representa a subjetividade humana (Gónzalez-Rey, 2002, p. 29).

Nessa proposta, a pesquisa qualitativa é comprometida de forma explícita com a teoria que a sustenta. Dessa maneira, a esquizoanálise nos permite examinar a família não só através do modo como os indivíduos se organizam e se socializam, mas também como um coletivo com capacidade para transformar, para deixar irromper novos territórios existenciais. As famílias dos portadores de transtorno mental habitam um território existencial cuja referência identitária é formada por linhas duras e estanques, mas que possui também linhas flexíveis, o que possibilita ao grupo ser afetado pelo que vem de "fora", dispositivo que aciona processos de subjetivação e escapa da reprodução do cotidiano em torno do sofrimento.

Utilizando esse raciocínio de imanência, de coexistência dessas linhas, esperamos alcançar nosso objetivo, que é conhecer essas famílias não a partir de sua psicopatologia, mas a partir de seus territórios existenciais, desvelando sua ligação ou não com a processualidade da vida, mediante a justaposição do plano de organização formado pelas linhas duras e repetitivas, que enlaçam a doença mental, e do plano de consistência, plano invisível de expansão da vida, onde as forças se articulam e se compõem a partir dos agenciamentos que a família estabelece, das relações entre as forças, para gerar novos sentidos (Romagnoli, 2005). Essa coexistência é examinada nos discursos dos familiares que deram seu depoimento acerca do seu dia-a-dia com o portador de transtorno mental, sendo investigados tanto a determinação do plano de organização, que subordina os fluxos do desejo a um modo de existência estabelecido, quanto a busca de conexões que brota dos encontros, do campo de afetamentos que permite uma recomposição desses fluxos.

A população da pesquisa foi composta pelas famílias de Betim que são atendidas pelo Centro de Referência em Saúde Mental - CERSAM Teresópolis, pelo Programa de Extensão em Saúde Mental, descrito anteriormente. A amostra foi não-probabilística por acessibilidade, portanto não apresenta fundamentação matemática, sendo destituída de rigor estatístico. Esse tipo de amostragem, também chamado de amostra acidental ou de conveniência, depende unicamente dos critérios do pesquisador, e corresponde à seleção dos “(...) elementos a que se tem acesso, admitindo que estes possam, de alguma forma, representar o universo" (Gil, 1991, p. 97). A amostragem dependeu da procura pelo serviço e foi definida a posteriori, a partir das entrevistas realizadas. Sendo assim, os sujeitos incluídos no estudo foram os familiares que preencheram o cadastro familiar, via encaminhamento, no primeiro semestre de 2004, levando-se em consideração o prazo de um ano, estabelecido pela instituição de fomento, para se realizar o estudo.

A coleta dos dados foi feita através de entrevistas semi-estruturadas, que seguiam o roteiro elaborado pelo cadastro familiar. $\mathrm{O}$ cadastro familiar funcionou como instrumento para o conhecimento tanto do público usuário do programa quanto do funcionamento das famílias atendidas, visando ao fornecimento de dados acerca da realidade desses grupos. Tal proposta surge da necessidade de montagem, atualização e organização de um conjunto de informações acerca das famílias que recorrem ao serviço de saúde mental, caracterizando-as quanto: à identidade, à idade, ao sexo, à profissão/atividade exercida, ao local de trabalho ou de exercício de atividade de qualquer natureza, à renda individual e familiar, à organização familiar, à dinâmica de funcionamento, ao tempo da eclosão do sintoma do paciente identificado, aos tratamentos anteriores, às tentativas de reorganização da família. Espera-se que esse cadastro contribua ainda para o redimensionamento do programa de extensão ao longo do tempo. 
O instrumental de análise dos dados obtidos no cadastro familiar se constituiu da análise de conteúdo e das respectivas categorias temáticas oriundas deste procedimento de interpretação. Sobre a análise de conteúdo, Bardin (1994) destaca que, possuindo modalidades distintas, esta técnica mescla duas orientações: a verificação meticulosa e a interpretação criativa, sempre em busca do que está além das aparências, do que se esconde por detrás das comunicações, formando um amálgama do qual fazem parte tanto a objetividade quanto a subjetividade. Da análise de conteúdo utilizamos mais precisamente a proposta acerca do sistema de categorias, com o intuito de organizar e sistematizar as questões investigadas provenientes das entrevistas semi-estruturadas. Sendo assim, o material foi codificado através das seguintes categorias temáticas: situação familiar, renda familiar, emergência da psicopatologia e dinâmica de funcionamento, previamente estabelecidas na elaboração do cadastro familiar.

Foram analisados oito cadastros familiares, preenchidos de março a setembro de 2004 pelos estagiários do programa de extensão Saúde Mental e Família. Nas entrevistas efetuadas com os responsáveis, nas quais a família tinha autonomia para decidir quem viria ao encontro, apenas em três delas o portador de transtorno mental participou. Nesse primeiro encontro com o doente e sua família, somente em duas das entrevistas estes colocaram suas impressões. Tendo em vista a população estudada e ciente de que a pesquisa poderia trazer riscos para os informantes, na realização da coleta de dados seguimos as diretrizes e normas para pesquisas envolvendo seres humanos, do Conselho Nacional de Saúde, regulamentadas pela Resolução 196/96 (Brasil, 1996).

\section{ANÁLISE E DISCUSSÃO DOS RESULTADOS}

Constatamos, na categoria situação familiar, que as famílias entrevistadas se constituíam tanto de famílias nucleares quanto de famílias alternativas, sendo 04 de cada grupo. As famílias nucleares, variando de vinte a trinta e sete anos de casados, demonstram a presença de uniões duradouras e formais nesse estrato social, com o funcionamento estudado por Sarti (2003). A autora evidencia os grupos familiares das camadas baixas como grupos hierárquicos, caracterizados pela precedência do homem sobre a mulher, dos pais sobre os filhos, dos mais velhos sobre os mais novos, seguindo um padrão de autoridade patriarcal. Cada uma dessas categorias possui seus papéis nitidamente definidos dentro da família, exercidos de maneira complementar. Geralmente o marido é o provedor, responsável pelo pagamento das contas da casa, e a mulher responde pelo serviço doméstico. Caso a mulher trabalhe, sua renda é apenas complementar, pois, de fato, é o homem que provê as necessidades básicas. Nas relações interpessoais, observa-se ainda uma forte preocupação moral, sendo a família um grande valor. Nas famílias dos portadores de transtorno mental, esse valor é solidificado, sendo que o cuidado e atenção ao membro doente são vistos como um dever a ser cumprido.

No que se refere às famílias alternativas, estas eram compostas pelos seguintes modelos familiares: uma união estável, sem filhos, com filhos e netos da mulher; uma união estável, com filhos; uma família de chefia feminina, na qual cada filho pertencia a uma união; e uma família de irmãos com a mãe doente vivendo como agregados de uma outra família nuclear. Nas uniões estáveis, estas eram consideradas pelos membros da família, sem diferenças do casamento oficial. A família com chefia feminina possuía um forte conflito com a família de origem, pois o fato de cada filho ser de um pai era visto pelas tias, irmãs da mãe do portador de transtorno mental, com forte conotação pejorativa. A família de agregados é um exemplo inegável de que não apenas a consangüinidade é levada em consideração para se definir o grupo. Sendo a mãe portadora de uma psicose orgânica degenerativa, com a morte do pai, os três filhos adolescentes foram viver com a madrinha de um deles, integrando a família desta. Estudando a transformação da família a partir de uma ótica institucionalista, Romagnoli (1996) salienta a presença do critério da convivência como definidor da família, o que denuncia uma atividade geradora do novo, na organização familiar que conta com a afetividade como seu sustentáculo, e não só com a consangüinidade.

Quanto ao tamanho, as famílias entrevistadas eram formadas de no mínimo três membros e no máximo de dez membros. Em geral, são famílias numerosas, que geraram de três a dez filhos. Esses grupos, usualmente, possuem relação com a família extensa, sendo comum a presença de netos e netas vivendo com a família, principalmente no caso da separação dos filhos. Além disso, também presenciamos o contrário, quando os pais tornam-se idosos e vão morar com os filhos. Às vezes os filhos se casam e também vão morar com os pais. É comum, nesses rearranjos, habitarem o mesmo lote, ou a mesma casa, em pavimentos distintos. 
Quanto ao ciclo vital, as famílias situam-se na fase dos filhos adultos, com exceção de uma família, que se encontra na fase dos filhos adolescentes, sendo a mãe o membro doente. Carter e McGoldrick (1995) destacam que, na fase da família com filhos adultos, o grupo encontra-se no momento de os filhos saírem de casa, seja para constituírem uma nova família, seja para cuidarem de sua própria vida. Nas famílias entrevistadas, alguns filhos já haviam saído de casa, mas outros tinham retornado à família de origem, quer por não conseguirem se sustentar sozinhos, quer por motivo de separação, além é claro, da instauração da doença mental. No último caso, esse movimento reforça a crença de que a família é responsável pelo cuidado do portador de transtorno mental. Cabe salientar que, no contexto da pobreza, as estratégias de sobrevivência implicam em somar recursos, viabilizando assim o sustento do grupo familiar.

Nesse estágio espera-se ainda da família um realinhamento de seus relacionamentos para que possam incluir em seu seio os parentes por afinidade e os netos. Além disso, o relacionamento entre os membros passa a ser de adulto com adulto. Nas famílias com membros portadores de transtorno mental essa autonomia não ocorre, como pudemos constatar não só nos cadastros analisados, mas também ao longo dos tratamentos efetuados. Quando o membro doente é um filho, há uma grande preocupação por parte dos pais com seu futuro, sobretudo quando eles não estiverem mais aqui para assegurar cuidado e sobrevivência. Por outro lado, quando o membro doente é um dos pais ou integrante do casal, há, por sua vez, uma sobrecarga dos filhos ou do outro cônjuge, que passa a desenvolver o cuidado para com ele.

Independentemente do subsistema familiar ao qual pertença o portador de transtorno mental - seja o subsistema filhos, o subsistema casal ou o subsistema pais -, é indiscutível que isso afeta todas as famílias, seja qual for a situação familiar em que se encontrem. Tanto os modelos nucleares quanto os modelos alternativos, tanto as famílias mais numerosas quanto as famílias menores, todas sofrem grandes alterações quando eclode a doença mental.

$\mathrm{Na}$ categoria renda familiar, verificamos que as famílias entrevistadas têm uma renda familiar de um a cinco salários-mínimos, o que as situa como pertencentes às camadas baixas da sociedade. Conforme Boudon e Bourricaud (1993), esse estrato social constitui-se como um estrato de baixo poder aquisitivo, possuindo moradia precária, baixa instrução e baixo nível de qualificação. Todavia, cabe ressaltar que esse resultado não é representativo das famílias da região e diverge dos dados apresentados pela Universidade Federal de Minas Gerais (2004), em pesquisa recente realizada na região, em que mais de $50 \%$ das famílias possuem renda de até três saláriosmínimos.

A família é a célula mestra da sociedade contemporânea, atuando não só para a continuação da existência dos indivíduos, mas também para a proteção e socialização de seus membros. O grupo é responsável pela sobrevivência cotidiana, reunindo recursos para a satisfação das necessidades básicas, desenvolvendo estratégias em que rendas são obtidas e agrupadas em um orçamento comum. De acordo com Carvalho e Almeida (2003), as condições financeiras das famílias de camadas baixas dependem da fase do ciclo vital e do número e características de seus membros - no caso das famílias estudadas, de possuírem ou não o Benefício de Prestação Continuada - BPC -, no valor de um saláriomínimo por mês, concedido quando preencher as condições necessárias para tal, ou mesmo aposentadoria por invalidez, quando é contribuinte por ocasião do seu adoecimento, ambos do Instituto Nacional de Seguridade Social - INSS.

No que se refere ao aspecto financeiro, percebemos nas famílias entrevistadas que o portador de doença mental ou é um sustentáculo da renda familiar (quando é beneficiado ou aposentado) ou é um peso a mais, para usufruir os escassos recursos existentes. Quando recebe o auxílio, seu dinheiro é bem-vindo para o grupo, sendo fundamental para a sobrevivência e a preservação do dia-a-dia. Geralmente sem condições de gerir sua renda, é o responsável pela família que realiza essa função. Observamos que, quando isso ocorre, o doente quase não apresenta gastos pessoais e não possui autonomia sobre o seu salário, recebendo (quando recebe) uma pequena quantia para gastos pessoais. Por sua vez, quando o portador de doença mental não tem nenhuma renda - o que acontece algumas vezes - tem condições de trabalhar, ele corresponde a um peso para a família, que se vê com mais um adulto para sustentar. Nesse sentido, as famílias que não possuem o benefício vivem em um esforço assíduo para consegui-lo. No entanto, na realidade, torna-se cada vez mais difícil adquirir essa concessão do Estado, o que é uma fonte de queixas e frustrações por parte dos familiares entrevistados.

$\mathrm{Na}$ categoria emergência da patologia, percebemos nos discursos familiares uma unanimidade na confirmação de um grande sofrimento por ocasião da eclosão da doença. Contrariamente ao imaginário social, que alia essa 
ocorrência a uma participação direta e voluntária da família, os relatos nos conduzem a momentos de desorientação e dor, a dificuldades de aceitação. Melman (2001) e Rosa (2003) realizaram pesquisas em universos semelhantes ao nosso, e também destacam que a emergência do transtorno mental conduz a família a um martírio, sustentado por não saber o que fazer, juntamente com uma forte sensação de fracasso. Todas as famílias revelaram também uma grande alteração na rotina, principalmente em função dos sintomas graves e da instabilidade que acompanham o transtorno mental.

Quando indagadas acerca do diagnóstico do membro doente, todas as famílias, sem exceção, apresentaram dificuldades em designá-lo. Quando chegavam a saber o nome da doença, não sabiam o que ele significava. Percebemos que não há uma preocupação dos agentes de saúde em informar, tampouco em explicar o que de fato o doente tem, e por outro lado, há uma dificuldade das famílias em perguntar e em pedir esclarecimentos. Analisando essa questão, evidenciamos um poder existente na informação e no saber, que contribuiu para um assujeitamento dessas famílias. Foucault (1999), ao afirmar que todo discurso revela um desejo e uma vontade de poder, leva-nos a pensar no exercício de submissão e dominação a que tal prática incita. Presenciamos, assim, não só o poder de diagnosticar, inerente à formação discursiva acerca da loucura, produzindo uma realidade social que separa os normais dos doentes mentais, mas também o poder sujeitando quem não sabe.

O saber e sua prática não só controlam e convocam uma realidade social, mas também distanciam os doentes e suas famílias das práticas de si, da experimentação. Esse poder exerce-se de forma constitutiva, moldando subjetividades e territórios existenciais. A escassez de relação consigo mesmo, sustentada pelo poder e pelo saber que vêm dos especialistas, torna a subjetividade mais propícia a ser normalizada pelas disciplinas. $\mathrm{O}$ fato de não possuírem uma formação universitária, de não terem o conhecimento do médico ou do psicólogo, impede os familiares de se reconhecerem como sujeitos autônomos, vinculando-os à identidade da "ignorância", tornando-os meros produtos do poder normalizador. Esse lugar de alienação impede novas experiências de si, dificulta a ocupação de um outro lugar pela família, o lugar de um grupo ativo no processo de construção da vida. Nesse contexto, todos se tornam passivos frente ao tratamento, impossibilitados de inventar, de tornar de sua vida uma obra de arte, arte entendida como ação transformadora, como defende Loureiro (2004).

Além disso, notamos que a falta de informação acerca da doença e de seus sintomas, em um âmbito mais geral, impossibilita, na maioria das vezes, a procura imediata pelo tratamento. Essa demora agravou o quadro do portador de transtorno mental em três das famílias entrevistadas. Em duas outras famílias, o nãoreconhecimento da doença mental e de seus sintomas levou a comportamentos de agressão física ao doente, como se seus atos fossem voluntários e denotassem desobediência.

Todas as famílias entrevistadas, com exceção de uma, reconhecem a importância do serviço. De maneira geral, possuem uma boa relação com o CERSAM Teresópolis, que é percebido como cooperativo com o doente e com a família. Embora acreditem que o tratamento produza efeitos positivos nos portadores de transtorno mental, o fato é que essas famílias devem fazer uma reorganização para conviver com a doença mental.

$\mathrm{Na}$ categoria dinâmica de funcionamento familiar ficou claro que todas as famílias entrevistadas estruturam seu cotidiano em torno da doença mental. Nas tentativas de reorganização frente a essa realidade, surgem respostas distintas, mas todas exigem um inevitável remanejamento. Essas mudanças afetam as relações entre os membros da família e podem alterar, inclusive, a convivência com a família extensa, que se afasta diante da instabilidade da doença mental, como foi assinalado por um familiar. Em outra família foi necessário alterar a ocupação dos cômodos da casa e deixar um quarto somente para o membro doente, disponibilizando um espaço inexistente. Conforme mencionaram os informantes, a modificação tanto na convivência familiar quanto na ocupação da casa se fez necessária pela sintomatologia apresentada, que mudou hábitos de sono, alimentação e humores.

Nesse sentido, podemos afirmar que não só a eclosão da doença, mas também a sua continuidade, exigem cuidados constantes por parte da família, como pontua Rosa (2003). Nos relatos analisados, a atenção dispensada pelas famílias dizia respeito à degeneração orgânica, à agressividade constante, ao risco de suicídio, à falta de higiene, às fugas e aos perigos da rua. Houve ainda a presença do risco de assassinato por traficantes, tendo-se em vista que uma das famílias possui um portador de transtorno mental que também é usuário de drogas. Todos esses processos são vivenciados pelos familiares com estresse e grande preocupação. 
A degeneração orgânica, presente nos portadores de transtorno mental de duas famílias, necessita de zelos permanentes com a higiene pessoal do doente, com a alimentação, com a ajuda para se vestir, com as saídas de casa. Foi-nos colocado que sempre é preciso haver alguém junto para a efetuação dessas atividades corriqueiras. Como esses quadros tendem a se agravar, há uma perspectiva de mais necessidade de cuidado e atenção. A marca da agressividade é uma constante na relação do portador de transtorno mental com a família. As brigas, algumas vezes com violência, passam a fazer parte do dia-a-dia do grupo e tornam tensas e difíceis as relações entre seus membros. As agressões ocorrem tanto com os pais quanto entre os irmãos e com os filhos. São comuns episódios de surto em que os pertences da casa são quebrados. Nessas situações as sensações de raiva e de desamparo são freqüentes, pois geralmente nem se conseguiu ainda saldar as prestações da aquisição do que foi danificado, ou quando já foi pago, torna-se pouco provável uma nova compra. Além das perdas materiais, há ainda o risco de suicídio, que aumenta mais ainda a tensão dos membros da família. Esse risco faz com que seja indispensável permanecer atento ao comportamento do membro doente, o que aumenta o trabalho e a sobrecarga física e subjetiva dos responsáveis.

Com uma rotina que não possibilita a contratação de uma empregada doméstica para a realização dos trabalhos em casa, ou mesmo para ajudar a tomar conta do portador de transtorno mental, com os graves sintomas que acompanham esses quadros, da família é exigido um grande esforço. Às vezes os membros chegam a abrir mão de sua própria vida, tendo em vista o excesso de cuidados dispensados ao doente. Como salientou Melman (2001), não raro as vidas próprias dos outros membros da família tornam-se sem investimento e empobrecidas. Rosa (2003) destaca em seu livro, a partir de uma abordagem de gênero, que o cuidado familiar ao portador de transtorno mental geralmente é e exercido por mulheres, que, sem notoriedade, concentram-se no universo privado e familiar e a esse cuidado dedicam sua vida, seu tempo, seus projetos pessoais. Observamos isso também em nossa pesquisa. Nos oito cadastros analisados, as mulheres se colocaram como responsáveis em todas as entrevistas. Em cinco famílias eram as mães, em uma família era a esposa, em uma família a irmã, e em uma a filha e a madrinha.

Quando se pergunta como é ter alguém nessa situação, afloram em todas as famílias sentimentos de vergonha e de tristeza e dificuldades tanto na convivência com o doente quanto com o meio social.
Conforme os depoimentos, o contato diário com a doença mental torna a vida pesada e árdua. É difícil aceitá-la, pois esta geralmente é associada a uma derrota parental e social. Há uma preocupação com os vizinhos e com o que eles vão pensar, sobretudo porque os sintomas não podem ser escondidos entre quatro paredes e se tornam explícitos. Nesse contexto, a vergonha por parte da família existe em cada membro e o constrangimento com a doença mental é permanente. A dor de ter que cuidar e prover uma pessoa que não pode tomar conta de si mesma e interfere ativamente no dia-a-dia de todos atravessa a dinâmica e o funcionamento familiar a todo o instante.

Para finalizar essa categoria, das oito famílias que responderam ao cadastro familiar, somente duas tiveram a experiência de internações anteriores do membro doente. Observamos que isso é uma conquista da luta antimanicomial, que desde os primórdios dos anos 1990 luta, institucionalmente e cotidianamente, pela extinção da "cultura manicomial", propondo serviços extra-hospitalares, fundamentando suas ações em uma ação multiprofissional e construindo uma nova mentalidade, que respeite a singularidade e o exercício da cidadania do portador de transtorno mental.

\section{CONSIDERAÇÕES FINAIS}

Esse estudo se propôs a analisar, de forma inicial, a dinâmica de funcionamento das famílias que estão sendo atendidas no CERSAM Teresópolis, município de Betim. Foram encontradas famílias presas à dor e à culpa, imersas na sobrecarga da convivência com a loucura em seu cotidiano. Nas famílias de baixa renda existem necessidades básicas - de alimentação, de saúde - que exigem estratégias para encarar situações cotidianas penosas. Esse enfrentamento endurece as subjetividades, que ocupam estratos sedimentados e, em alguns momentos, estéreis. Em meio ao território existencial cristalizado da pobreza, que, sem dúvida, tem grandes carências, as subjetividades tendem a sustentar a marca da privação. Como vimos na introdução, ao plano de organização correspondem as imagens sociais, as idéias vigentes, o território existencial pronto e perpetuado no dia-a-dia. Entretanto, por mais codificado e reprodutivo que seja, esse plano não domina completamente o plano de consistência, o plano de expansão da vida. Todavia, essa possibilidade apresenta-se diminuta em nosso universo de pesquisa.

Como pudemos notar nos relatos analisados, há uma identidade familiar, partilhada por todas as famílias entrevistadas, fundamentada no sofrimento e 
sustentada por todos os membros da família, impedindo a construção de outra forma de conviver em família. De fato, a baixa renda familiar, a cronicidade da doença mental e sua respectiva dependência, a necessidade de cuidado ininterrupto, a crise que advém da eclosão da doença, tudo isso afeta as subjetividades envolvidas, formando um modo de existência grupal que tem na doença mental seu eixo de sustentação. Como vimos, essa realidade incentiva um modo de funcionamento estereotipado e repetitivo que empobrece as reais possibilidades da vida.

Esse endurecimento da família e a insistência nessa identidade podem ser compreendidos como um sintoma familiar, no sentido utilizado por Romagnoli (2004a). A autora, a partir de uma abordagem esquizoanalítica do sintoma, ressalta que este se associa a um arraigamento, a uma fixação ao território existencial vigente, quando a família se vê diante de uma ruptura de sentido. A família, ao viver a experiência de desestabilização propiciada pela emergência da doença mental, ao invés de se abrir para um enfrentamento do novo, insiste na repetição. Essa repetição caracteriza, na verdade, a negação da heterogeneidade desse território, a limitação das suas dimensões crescentes a um número reduzido e conhecido de conexões. Essa fixação incrementa agenciamentos redundantes e arraigados, que passam a atuar para a destruição das singularidades, para a perda da diversidade, para a interrupção de linhas processuais da subjetividade.

O sintoma familiar, entendido dessa maneira, envolve grande sofrimento psíquico e subjetivo por parte de todos os membros do grupo. Esse sofrimento é assíduo, sobretudo porque, no nosso universo de pesquisa, é nessa rede social que grande parte dos sujeitos estudados garante alguma convivência e uma inserção social. Sem dúvida, conviver com a doença mental é desgastante para a família. De forma alguma estamos ignorando essa situação, ou a desmerecendo. Contudo, realizando uma análise a partir do plano de organização e do plano de consistência presentes nessa realidade, podemos afirmar que há uma prática defensiva por parte das famílias, nesse enfrentamento. Partindo do raciocínio de que esses dois planos possuem uma relação de justaposição, na qual o que está estratificado encontra-se mergulhado em uma dimensão inacabada, e por outro lado, essa dimensão informe incute inventividade a tudo o que já está estabelecido, acreditamos que as famílias entrevistadas estão presas ao plano de organização que as coloca em um lugar de culpabilização e de derrota.
Com base nas idéias de Deleuze e Guattari (1995), consideramos que a subjetividade tem como essência a potência da vida, que possui uma dimensão criadora, intensa, heterogênea, que estala nos encontros efetuando agenciamentos, produzindo acontecimentos mediante a afirmação de singularidades. Todavia, no nosso entender, nos grupos estudados, essa potência encontra-se encapsulada em um circuito defensivo de dor e de sofrimento, operando para a reprodução de um único modo de existência. Nesse sentido, a vibração intensiva da vida, a composição dos papéis e funções dos membros da família, a distribuição da sua rotina, o peso econômico e subjetivo cristalizam-se, estratificam-se, submetem-se ao plano de organização, empobrecendo o território familiar, que se torna enfraquecido pela realidade da mesmice e do igual e indisponível para suportar o movimento e as diferenças. Ao invés de essa vibração atuar como uma diferença que remete a outra diferença, ela é usada, dessa maneira, como defesa contra a mutação própria da vida. Destituídas de seu poder-potência, as famílias insistem em trazer à tona o "como eram", em um vão ensaio de conter o tempo, a história, os afetamentos, a exterioridade das forças que nelas atuam.

Para ocorrer a criação de um novo território existencial é necessário haver uma desterritorialização do escudo contra a doença mental e seu cotidiano pesado, calcada em muito trabalho e em muita penúria. Quando a família cria um arranjo absolutamente novo, atinge um princípio de individuação imanente e autônomo a partir de si: autopoiese. A força é efetuada e é também criado um plano de consistência, de composição, juntamente com a invenção de um novo território para que essa força se efetue. Esta desterritorialização possibilita ao território existencial livrar-se da defesa, que, enquanto repetição, caracteriza, na verdade, a negação da heterogeneidade desse território, a limitação das suas dimensões crescentes a um número reduzido, previsível e conhecido de conexões.

Como evidenciamos ao longo do estudo, a realidade desses grupos é, na maioria das vezes, uma realidade dura, tendo-se em vista a seriedade da doença e a longa duração dos sintomas embasada no cuidado constante da família. As dificuldades de comunicação e interação do doente mental são freqüentes, além de os fracassos sociais serem contínuos. No entanto, retornando-se ao programa de extensão ao qual esta pesquisa está atrelada, o alargamento do campo terapêutico, ao promover um atendimento ao grupo familiar, opera a favor da invenção, retirando as famílias do isolamento e da culpa solitária, e dribla a necessidade de explicar o fenômeno do adoecer psíquico culpabilizando e 
responsabilizando esses grupos, como denuncia Romagnoli (2004b). Apostamos, assim, que é possível a criação de um novo território existencial de um outro funcionamento, de um outro modo de conviver com a doença mental. Esse é o grande desafio do atendimento familiar na rede de saúde mental: fazer desse cuidado, não um fardo, mas uma forma de subjetivação, de união; fazer emergir, a partir desse cuidado, as linhas flexíveis da subjetividade, para compor formas de subjetivação singulares em cada grupo atendido.

\section{REFERÊNCIAS}

Bardin, L. (1994). Análise de conteúdo. Lisboa: Edições 70.

Boudon, R. \& Bourricaud, F. (1993). Estratificação social. Em Dicionário Crítico de Sociologia. (p. 214). São Paulo: Ática.

Brasil. (1996). Ministério da Saúde. Resolução 196, de 10 de outubro de 1996. Dispõe sobre as diretrizes e normas regulamentadoras de pesquisa envolvendo seres humanos. Disponível em: <http://www.conselho.saude.gov.br> (Acesso em 20/02/2004)

Carter, B. \& McGoldrick, M. (1995, $2^{\text {a }}$ ed.). As mudanças no ciclo de vida familiar: uma estrutura para a terapia familiar. Em B. Carter \& M. McGoldrick. As mudanças no ciclo de vida familiar. (pp. 07 - 29). Porto Alegre: Artes Médicas.

Carvalho, I. M. M. \& Almeida, P. H. (2003). Família e proteção social. Perspectiva, 17(2). Disponível em: http://www.scielo.br. (Acesso em 15/09/2004).

Deleuze, G. \& Guattari, F. (1995). Mil Platôs: capitalismo e esquizofrenia. Rio de Janeiro: Editora 34.

Deleuze, G. \& Guattari, F. (1996). 1933: micropolítica e segmentaridade. Em G. Deleuze \& F. Guattari. Mil Platôs: capitalismo e esquizofrenia. (Vol. 3, pp. 83-115). Rio de Janeiro: Editora 34.

Deleuze, G. \& Guattari, F. (1997). Conclusão: regras concretas e máquinas abstratas. Em G. Deleuze \& F. Guattari. Mil Platôs: capitalismo e esquizofrenia. (Vol. 5, pp. 215-234). São Paulo: Editora 34.

Deleuze, G. \& Parnet, C. (1998). Políticas. Em G. Deleuze \& C. Parnet. Diálogos. (pp. 144 - 170). São Paulo: Escuta.

Foucault, M. (1999, 14 ed.). Microfísica do poder. Rio de Janeiro: Graal.
Gil, A. C. (1991, 3 ed.). Métodos e técnicas de pesquisa social. São Paulo: Atlas.

Gónzalez-Rey, F. L. (2002). Pesquisa qualitativa em Psicologia. São Paulo: Pioneira Thomson Learning.

Guattari, F. (1992). Caosmose: um novo paradigma estético. Rio de Janeiro: Editora 34.

Loureiro, I. (2004). Arte e beleza: diferentes formulações foucaultianas sobre a estética da existência. Revista do Departamento de Psicologia - UFF, 16(1), 4153.

Melman, J. (2001). Família e doença mental: repensando a relação entre profissionais de saúde e familiares. São Paulo: Escrituras.

Rolnik, S. (1999). Novas figuras do caos: mutações na subjetividade contemporânea. Em L. Santaella \& J.A.Vieira (Orgs.), Caos e ordem na Filosofia e nas Ciências. (pp. 206-221). São Paulo: FACE/ FAPESP.

Romagnoli, R. C. (1996). Novas Formações Familiares: uma leitura institucionalista. Dissertação de Mestrado NãoPublicada, Programa de Pós-Graduação em Psicologia Social, Universidade Federal de Minas Gerais, Belo Horizonte.

Romagnoli, R. C. (2004a). O sintoma da família: excesso, sofrimento e defesa. Interações, 9(18), 41-60.

Romagnoli, R. C. (2004b). Trabalhando com famílias na rede de saúde mental: dificuldades e desafios. Pulsional, 17(180), 71-80.

Romagnoli, R. C. (2005). Famílias na rede de saúde mental e esquizoanálise: uma aproximação possível. Em T. FéresCarneiro (Org.), Família e casal: efeitos da contemporaneidade. (pp. 251 - 265). Rio de Janeiro: Editora PUC-Rio.

Rosa, L. C. S. (2003). Transtorno mental e o cuidado na família. São Paulo: Cortez.

Sarti, C. A. (2003, $2^{\text {a }}$ ed.). A família como espelho: um estudo sobre a moral dos pobres. São Paulo: Cortez.

Universidade Federal de Minas Gerais - UFMG. (2004). Pesquisa sobre a Assistência Social em Betim. (Relatório de pesquisa). Belo Horizonte: Departamento de Ciência Política da UFMG.

Recebido em 04/07/2005 Aceito em 12/05/2006

Endereço para correspondência: Roberta Carvalho Romagnoli. Rua Terra Nova, 101/401 Sion, CEP 30315-470, Belo HorizonteMG. E-mail: robertaroma@uol.com.br 